\title{
MICROENCAPSULAÇÃO DO LICOPENO COM CICLODEXTRINAS ${ }^{1}$
}

\author{
Graciette MATIOLI² ${ }^{\star}$, Delia B. RODRIGUEZ-AMAYA ${ }^{3}$
}

\section{RESUMO}

O licopeno é uma das importantes substâncias naturais de coloração industrial de alimentos. Além disso, este carotenóide tem importância em saúde humana pela sua atuação na redução de riscos de doenças crônicas como câncer, em especial de próstata, e doenças cardiovasculares. No entanto, pelo alto grau de insaturação, o licopeno é propenso à isomerização e oxidação. Neste trabalho a microencapsulação do licopeno foi estudada, utilizando as ciclodextrinas (CDs) como substâncias encapsulantes. Extraído da goiaba e isolado em coluna aberta, o licopeno dissolvido em acetona foi adicionado a $\alpha$-, $\beta$ - e $\gamma$-CD dissolvidas em água, a acetona sendo posteriormente eliminada com auxílio de nitrogênio. Inicialmente, foi investigada a complexação com as três CDs em razão molar licopeno:CD de 1:50. O licopeno formou complexo com a $\beta$ - e a $\gamma-\mathrm{CD}$, mas não com a $\alpha$-CD. Após 180 dias de estocagem a temperatura de refrigeração $\left(15^{\circ} \mathrm{C}\right)$, o licopeno se manteve constante no complexo licopeno- $\gamma$-CD e reduziu cerca de $80 \%$ no complexo licopeno- $\beta$-CD. Avaliando a melhor razão molar licopeno-CD, a inclusão foi máxima com o emprego da $\gamma$-CD e quando a razão molar foi de 1:200. O complexo mostrou-se dispersivel em água, mantendo a cor vermelha do licopeno. A estabilidade à luz, mostrou-se excelente, tendo $100 \%$ de retenção em 40 dias de monitoramento a temperatura ambiente.

Palavras-chave: licopeno; ciclodextrina; microencapsulação.

\section{SUMMARY}

MICROENCAPSULATION OF LYCOPENE WITH CYCLODEXTRINS. Lycopene is one of the important natural substances for industrial coloring of foods. In addition, this carotenoid has importance in human health because of its role in reducing the risk of chronic diseases such as cancer, especially prostate cancer, and cardiovascular diseases. However, because of its high degree of insaturation, it is prone to isomerization and oxidation. In this work, microencapsulation of lycopene was studied, utilizing cyclodextrins (CDs) as encapsulating substances. Extracted from guava and isolated in open column, lycopene in acetone was added to the $\alpha$-, $\beta$-, and $\gamma$-CD dissolved in water, acetone being subsequently eliminated with nitrogen. Initially, complexation was investigated with the three CDs at a molar ratio of 1:50. Lycopene formed complexes with $\beta$ - and $\gamma$-CD, but not with $\alpha$-CD. After 180 days of storage at refrigeration temperature, lycopene levels remained constant in the lycopene- $\gamma$-CD complex, but were reduced by $80 \%$ in the lycopene- $\beta$-CD complex. During evaluation of the best molar ratio of lycopene-CD, inclusion was maximum with $\gamma$-CD at a molar ratio of 1:200. The complex was dispersible in water, maintaining the red color of lycopene. Stability under light exposure was excellent, retention being $100 \%$ during 40 days of monitoring at ambient temperature.

Keywords: lycopene; cyclodextrins; microencapsulation.

\section{1 - INTRODUÇÃO}

Os carotenóides compõem um grupo de compostos responsáveis pelas cores amarela, laranja e vermelha de muitos alimentos de origem vegetal e alguns de origem animal. São também citados como responsáveis pela diminuição do risco de doenças como câncer e doenças cardiovasculares [16].

Um sistema de duplas ligações conjugadas constitui o cromóforo responsável pelo poder corante dos carotenóides e, também pela sua atuação contra doenças degenerativas. No entanto, este mesmo sistema é causa da sua instabilidade, e a preservação de carotenóides durante processamento e estocagem é um desafio e uma grande preocupação na área [10].

Entre os carotenóides, o licopeno vem sendo o destaque pela sua possivel ação contra o câncer, especialmente de próstata, e doenças cardiovasculares [1, 6]. É

1. Recebido para publicação em 07/02/2002. Aceito para publicação em 02/09/2003 (000830)

2 UEM - Depto. Farmácia e Farmacologia, Av. Colombo, 5790, CEP 87020 9000, Maringá, PR. Email: gmatioli@uem.br

${ }^{3}$ UNICAMP Faculdade de Eng. de Alimentos - Depto. Ciências de Alimentos. Campinas, SP.E-mail: delia@fea.unicamp.br

* A quem a correspondência deve ser enviada. responsável pela cor vermelha do tomate, melancia, goiaba vermelha, mamão vermelho e pitanga [16]. Embora não tenha atividade pró-vitamínica $\mathrm{A}$, este carotenóide é capaz de funcionar como um antioxidante, com capacidade de seqüestrar oxigênio singleto, duas vezes melhor que o $\beta$-caroteno e dez vezes melhor que o $\alpha$-tocoferol [3].

É desejável para muitas das aplicações que os carotenóides estivessem presentes na forma dispersivel em água. Isto é particularmente importante para utilizar seu poder de coloração em diversos gêneros alimentícios [8].

Hoje, estudos estão sendo feitos para proteger os pigmentos instáveis por encapsulação, suspensão ou pelo uso de outros antioxidantes naturais [8]. Ao mesmo tempo a encapsulação é desejável para tornar carotenóides dispersiveis em água.

A microencapsulação é um processo físico no qual um filme fino ou camada polimérica é aplicada para envolver sólidos, liquidos ou gases, isolando-os e protegendo-os das condições ambientais como luz, ar e umidade. Várias técnicas e agentes encapsulantes vêm sendo sugeridos $[9,12]$. Houve na última década um grande progresso no desenvolvimento de ingredientes microencapsulados [5, 7]. Os estudos encontram-se avançados em relação ao aroma, mas ainda limitados em termos de corantes. 
WAGNER \& WARTHESEN [15] constataram que os carotenóides de cenoura desidratada por atomização ("spray-drying") são estabilizados quando encapsulados com amido hidrolisado de diferentes equivalentes de dextrose (ED). O aumento na proporção do agente encapsulante, bem como de sua $\mathrm{ED}$, reduziram a degradação do carotenóide.

DESOBRY, NETO e LABUZA [2] compararam o efeito de três processos de secagem na encapsulação do $\beta$ caroteno sintético com maltodextrina ED 25. O carotenóide encapsulado apresentou-se mais estável quando a secagem em tambor rotativo foi realizada, comparada com secagem por liofilização e atomização.

As ciclodextrinas (CDs) são substâncias obtidas a partir do amido, e são muito adequadas para microencapsulação por inclusão molecular. São formadas por um número variável de unidades de glucose unidas entre si por ligações $\alpha-1,4$. As mais comuns são $\alpha-C D$, $\beta-C D$ e $\gamma-C D$, com 6,7 e 8 unidades de glucose, respectivamente [4]. Têm a forma de um cone truncado com uma cavidade hidrofóbica no centro. Externamente as CDs são hidrofilicas, sendo, portanto, solúveis em água. Devido à hidrofobicidade da cavidade interna das CDs, moléculas hidrofóbicas podem penetrar e se ligar no seu interior, desde que as dimensões das moléculas sejam compativeis com o tamanho da cavidade [13].

UKAI et al. [14] estudaram a solubilização em água e a estabilização do licopeno de tomate complexado com $\gamma$-CD. A estabilização deste complexo foi avaliada empregando-se ácido ascórbico ou glúten, e monitorada por um período de 4 dias. Foi obtida, em relação ao controle, uma estabilização de 5\% e 40\% quando do emprego de ácido ascórbico e glúten, respectivamente. Com relação à inclusão, esta foi máxima com a razão molar licopeno: $\gamma$-CD de 1:200.

Neste trabalho, com o objetivo de estabilizar o licopeno, ao mesmo tempo torná-lo dispersivel em água, foi realizada a sua microencapsulação, utilizando os três tipos de CDs como agentes encapsulantes.

Também foi feita uma avaliação da melhor razão molar do complexo de inclusão licopeno-CD e a sua estabilidade à luz.

\section{2 - MATERIAL E MÉTODOS}

\section{1 - Obtenção do licopeno}

O licopeno utilizado neste trabalho foi obtido da goiaba vermelha in natura da variedade Paluma e Ogawa fornecidas pela empresa Goiabrás (Associação Brasileira dos Produtores de Goiabas) localizada no Estado de São de Paulo. Optou-se por este fruto tropical rico em carotenóides, em especial o licopeno, pois o Brasil é um dos maiores produtores.

A goiaba (cerca de $1 \mathrm{~kg}$ ) foi inicialmente triturada em liquidificador até se obter uma massa homogênea. Foram adicionadas celite e acetona gelada até consistência pastosa da massa, e o material novamente triturado. Utilizando funil de vidro sinterizado e sucção, foi realiza- da a filtração. O material retido no filtro foi lavado mais vezes com acetona para retirar todo carotenóide (geralmente três vezes é suficiente). Os carotenóides foram então transferidos para éter de petróleo em funil de separação. Água destilada foi lentamente adicionada à parede do funil e duas fases foram formadas. A fase inferior presente no funil, correspondente a água e acetona, foi descartada, sendo a fase superior, contendo os carotenóides e éter de petróleo, novamente submetida a lavagem com água destilada. Este processo foi repetido seis a oito vezes, até total eliminação da acetona [10].

O licopeno foi extraído dos demais carotenóides e purificado através de cromatografia em coluna aberta de MgO:hiflosupercel (1:2), segundo metodologia de RODRIGUEZ-AMAYA [10]. Primeiramente foi utilizado evaporador rotativo para eliminar parte do éter de petróleo e concentrar os carotenoides. Este conteúdo concentrado foi adicionado no topo da coluna e a fase móvel (acetona:éter de petróleo na proporção de 10:90) foi adicionada. Conforme a necessidade, a quantidade de acetona da fase móvel foi sendo aumentada até total separação do licopeno e sua recuperação em funil de vidro sinterizado. Para melhor purificação do carotenóide, o volume inicial coletado da coluna foi descartado. O licopeno presente na solução de éter de petróleo e acetona foi então transferido para funil de separação e lavagens com água destilada foram realizadas até total eliminação da acetona. Esta solução foi transferida para balão volumétrico e a quantificação do licopeno presente em éter de petróleo foi realizada espectrofotometricamente em um espectrofotômetro Beckman, modelo DU 640, através da absorção no comprimento de onda de absorção máxima (469nm).

A pureza da solução de éter de petróleo contendo o licopeno foi verificada por cromatografia líquida de alta eficiência (CLAE). Uma alíquota $3,0 \mathrm{~mL}$ da solução de éter de petróleo contendo o licopeno foi evaporada com nitrogênio e o resíduo dissolvido em $1,0 \mathrm{~mL}$ de acetona. O volume de $10 \mu \mathrm{L}$ foi injetado no cromatógrafo líquido da marca Varian, modelo 9010, munido de coluna Vydac $\mathrm{C}_{18}$, acoplado a um detector de arranjo de fotodiodos Waters 994 e integrador mode1o 5200. A faixa de comprimento de onda utilizada foi de 300 a 550nm. Como fase móvel, foi empregado um sistema isocrático de tetrahidrofurano: $\mathrm{H}_{2} \mathrm{O}: \mathrm{MeOH}$ (15:4:81, v/v), com fluxo de 0,5mL/min [10].

$\mathrm{Na}$ fração de $10 \mu \mathrm{L}$ injetada ocorreu a separação dos carotenóides e obtida a somatória total das áreas, o que permitiu calcular a porcentagem de licopeno presente na solução.

A identificação do licopeno foi feita combinando-se tempo de retenção, o espectro de absorção na região do visivel e o comportamento cromatográfico por CLAE com detector de arranjo de fotodiodos. Esta identificação foi discutida em outros trabalhos [10, 11].

\section{2 - Microencapsulação}

A microencapsulação foi realizada com os três tipos de CDs: $\alpha-, \beta$ - e $\gamma$-CD (Sigma Chemical Company, EUA). 
A razão molar licopeno: $C D$ utilizada inicialmente foi 1:50. Em um tubo de ensaio com rosca foi colocado $2,5 \mathrm{~mL}$ de licopeno (1mg) em éter de petróleo. O éter foi posteriormente eliminado com nitrogênio gasoso. O licopeno foi dissolvido em $2,5 \mathrm{~mL}$ de acetona, utilizando ultrasom para total solubilização. Pesou-se as CDs $(90,7 \mathrm{mg}$ de $\alpha$-CD, $105,7 \mathrm{mg}$ de $\beta$-CD e $120,8 \mathrm{mg}$ de $\gamma$-CD) que posteriormente foram dissolvidas em $2,5 \mathrm{~mL}$ de água e, a seguir foram adicionadas a cada tubo contendo o licopeno dissolvido em acetona. A acetona foi posteriormente eliminada com nitrogênio. Os tubos mantidos sob refrigeração $\left(15^{\circ} \mathrm{C}\right)$ por seis meses foram periodicamente (a cada mês) avaliados espectrofotometricamente quanto à mudança de cor. Com a finalidade de se verificar a melhor razão molar licopeno: $\mathrm{CD}$, as seguintes proporções foram avaliadas espectrofotometricamente: 1:50, $1: 100,1: 150,1: 200,1: 250$.

\section{3 - Estabilidade à luz}

Após a microencapsulação, 3mL do complexo de inclusão licopeno- $\gamma$-CD, razão molar 1:200, foram acondicionados em frascos de vidro transparentes em atmosfera de nitrogênio. Os frascos foram fechados com tampas de borracha e teflon em anilhas de aluminio. Estes foram expostos à luz fluorescente de 318 lux de luminosidade e temperatura ambiente $\left(25-35^{\circ} \mathrm{C}\right)$ durante 60 dias. O mesmo procedimento foi realizado para frascos de vidro âmbar envoltos em papel aluminio e também em atmosfera de nitrogênio, sendo estes mantidos no escuro e temperatura ambiente. A cada 5 dias o conteúdo de um frasco mantido na luz e um mantido no escuro foram analisados espectrofotometricamente quanto à quantidade de licopeno remanescente, através da absorção no comprimento de onda de absorção máxima. Previamente a quantificação do licopeno, o complexo licopeno- $\gamma$-CD foi desfeito com o uso de hexano, ou seja, $2,5 \mathrm{~mL}$ do complexo de inclusão presente nos frascos foram transferidos para tubo de ensaio e acrescidos de $25 \mathrm{~mL}$ de hexano. O tubo foi selado e submetido a agitação em agitador mecânico por 30 minutos a 500rpm, conforme metodologia de DESOBRY, NETO \& LABUZA [2].

As análises das amostras foram realizadas em triplicata. O delineamento experimental utilizado foi do tipo inteiramente casualizado, onde a distribuição das amostras expostas à luz e no escuro obedeceu a um sorteio aleatório.

\section{3 - RESULTADOS E DISCUSSÃO}

O licopeno utilizado para microencapsulação teve uma pureza de 96,8\%, como apresentado no cromatograma obtido por CLAE (Figura 1), com base na separação dos carotenóides e somatória total das áreas.

A microencapsulação do licopeno foi possivel com o uso da $\beta$ - ou $\gamma$-CD. Com o uso da $\alpha$-CD a microencapsulação não aconteceu, o licopeno ficando na superficie da solução. Com $\beta-C D$ a microencapsulação resultou numa solução laranja clara com um precipitado no fundo do tubo. Com $\gamma$-CD, a solução se apresentou la- ranja forte sem precipitado no tubo. Ambos complexos mantiveram-se dispersiveis em água.

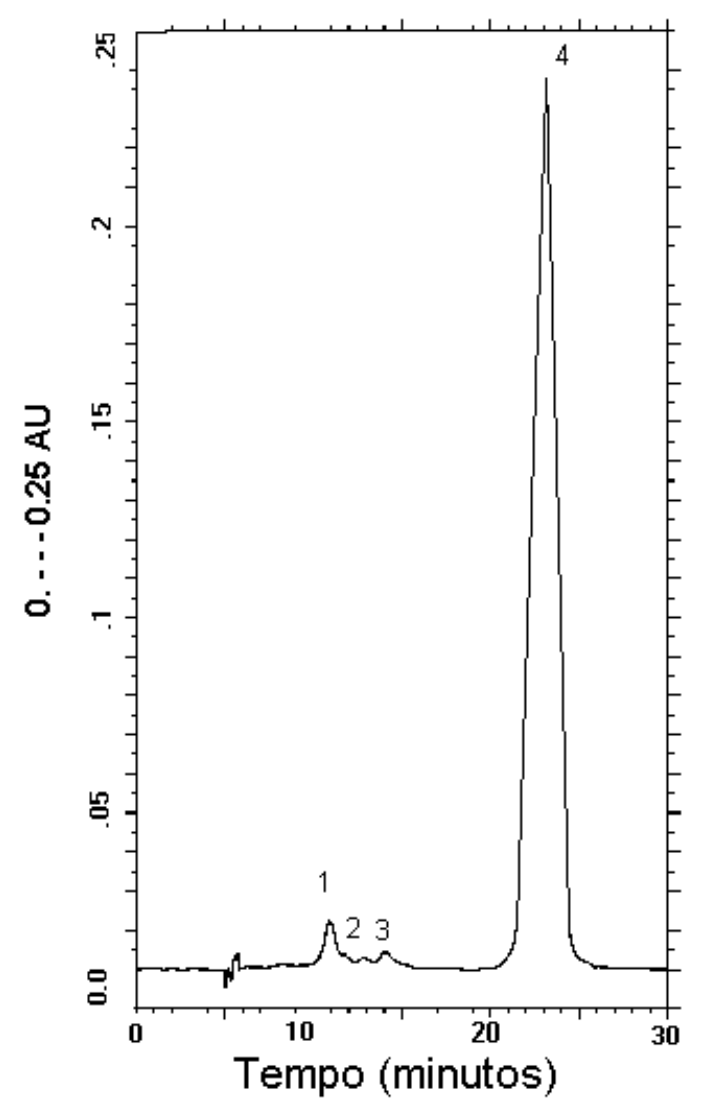

FIGURA 1: Cromatograma obtido por CLAE do licopeno extraído de goiaba. [Pico 4 - licopeno].

O licopeno microencapsulado com $\gamma$-CD não sofreu alterações (cor, por exemplo), e, após seis meses de realização dos testes manteve a cor original, acompanhada espectrofotometricamente. Contudo, verificou-se que o licopeno complexado com $\beta$-CD foi reduzido em torno de $80 \%$, no mesmo período .

As $\beta$ - e $\gamma$-CDs são substâncias passiveis de serem utilizadas como microencapsulantes do licopeno, pois, em solução aquosa as moléculas de água no interior do anel da CD são facilmente substituídas por moléculas apolares (licopeno), formando estruturas que são energeticamente mais estáveis. Contudo, a melhor CD para realizar esta microencapsulação é a $\gamma$-CD. Isto se deve ao diâmetro interno da cavidade da molécula (75-83 nm) maior que as demais CDs por apresentar 8 unidades de glucose, em detrimento a $\beta$-CD com 7 (60-65 nm) e $\alpha$-CD com 6 (47-53 nm) unidades [13].

Ao se avaliar a melhor razão molar licopeno- $\beta-C D$, através do aumento na proporção de CD (1:50, 1:100, $1: 150,1: 200,1: 250)$, verificou-se, visualmente e espectrofotometricamente, que quanto maior a quantidade de $C D$, melhor a microencapsulação, embora com posterior formação de precipitado no fundo do tubo para todas as razões testadas. Quando do emprego de 
$\gamma$-CD, verificou-se que à medida que se aumentava a quantidade de $\gamma$-CD, também se aumentava a intensidade da cor laranja, chegando ao vermelho, sendo que a melhor razão molar licopeno- $\gamma$-CD foi 1:200 ou acima, sem formação de precipitados. Este resultado está de acordo com o estudo de UKAI et al. [14] com licopeno de tomate, que também mostraram a razão molar de 1:200 com a $\gamma$-CD melhor para complexação e dispersão em água.

Após 40 dias na presença e ausência de luz, o licopeno complexado com $\gamma$-CD (razão molar 1:200) manteve-se estável à luz, sem apresentar degradação, confirmando a capacidade da $\gamma-\mathrm{CD}$ em encapsular o licopeno e mantê-lo retido no interior de sua cavidade. Esta representa uma estabilidade excelente, considerando que a luz é um dos fatores mais influentes na degradação dos carotenóides.

WAGNER e WARTHESEN [15] também observaram que a presença de luz não acelerou a degradação de carotenóides de cenoura encapsulados com amido solúvel, contudo a exposição ao oxigênio foi crítica na estabilidade destes carotenóides.

\section{4 - CONCLUSÕES}

Este trabalho mostrou o grande desempenho da $\gamma$-CD na estabilização do licopeno, uma vez que este carotenóide ao ser extraído da fruta apresenta-se extremamente instável e sujeito a degradações, devido ao seu alto grau de insaturação, que o torna susceptivel a isomerização e degradação oxidativa. Uma vantagem adicional é a microencapsulação por inclusão molecular, que pode ser realizada a temperatura ambiente, sem a necessidade do emprego de equipamentos específicos e de alto custo, evitando isomerização da molécula de licopeno e perdas durante o processo. O problema é a quantidade requerida e o preço da $\gamma-\mathrm{CD}$, que atualmente apresenta-se bem mais elevado em relação a $\alpha-C D$, e ainda maior em relação a $\beta$-CD. Por isso que, como continuação deste estudo, está sendo desenvolvida tecnologia própria para a produção das CDs.

\section{5 - REFERÊNCIAS BIBLIOGRÁFICAS}

[1] CLinton, S.K. Lycopene: Chemistry, biology, and implications for human health and disease. Nutr. Rev., v. 56, n. 2, p. 35-51, 1998.
[2] DESOBRY, S.A.; NETTO, F.M.; LABUZA, T.P. Comparison of spray-drying, drum-drying and freezedrying for b-carotene encapsulation and preservation. J. Food Sci., v. 62, n. 6, p. 1158-1162, 1997.

[3] DI MASCIO, P.; MURPHY, M.C.; SIES, H. Antioxidant defense systems, the role of carotenoid, tocopherol and thiols. Am. J. Clin. Nutr. (Supp1.), v. 53, p. 194-200, 1991.

[4] FRÖMMING, K.H.; SZEJTLI, J. Cyclodextrin in Pharmacy. Kluwer Academic Publishers, Dordrecht, 1994, 224p.

[5] JACKSON, L.S.; LEE, K. Microencapsulation and the food industry. Lebensm.-Wiss.u.-Technol., v. 24, p. 289-297, 1991.

[6] NGUYEN, M.L.; SCHWARTZ, S.J. Lycopene: Chemical and biological properties. Food Technol., v. 53, n. 2, p. $38-45,1999$.

[7] POPPLEWELL, L.M.; BLACK, J.M.; NORRIS, L.M.; PORZIO, M. Encapsulation system for flavors and colors. Food Technol., v. 49, p. 76-82, 1995.

[8] PSZCZOLA, D.E. Natural colors: pigments of imagination. Food Technol., v. 52, n.6, p. 70-82, 1998.

[9] RÉ, M.J. Microencapsulation by spray drying. Drying Technol., v. 16, n. 6, p. 1195-1236, 1998.

[10] Rodriguez-AMAYA, D.B. A Guide to Carotenoid Analysis in Food. ILSI Press, Washington, 1999, pp. 37-51.

[11] RODRIGUEZ-AMAYA, D.B.; RAYMUNDO, L.C.; LEE, T.; SIMPSON K.L.; CHICHESTER, C.O. Carotenoid pigment changes in ripening Momordica charantia fruits. Ann. Bot., v.40, p. 615-624, 1976.

[12] SHAHIDI, F.; HAN, X.Q. Encapsulation of food ingredients. Crit. Rev. Food Sci. Nutr., v. 33, n.6, p. 501-547, 1993.

[13] SZEJTLI, J. Cyclodextrins and the molecular encapsulation. Chim. Oggi, v. 3, p.17-21, 1987.

[14] UKAI, N.; NAKAMURA, H.; LU, Y.; ETOH, H.; OHSHIMA, s.; SAKAMOTO, H., ISHIGURO, Y. The watersolubilization and stabilization of lycopene by cyclodextrin and addition of protein. Nippon Shokuhin Kagaku Kogaku Kaishi, v. 43, p. 247-250, 1996.

[15] WAGNER, L.A; WARTHESEN, J.J. Stability of spraydried encapsulated carrot carotenes. J. Food Sci., v. 60, n. 5, p. 1048-1053, 1995.

[16] WONG, D.W.S. Química de los alimentos: mecanismos y teoria. Editorial Acribia S.A., Zaragoza, 1995, pp. 165-215.

\section{6 - AGRADECIMENTOS}

Os autores agradecem a bolsa de pós-doutoramento concedida a primeira autora pela CAPES e o apoio financeiro do MCT, através do projeto PRONEX (CNPq $\left.\mathrm{n}^{\circ} \cdot 662307 / 1996-8\right)$. 